\title{
Subunits Rip1p and Cox9p of the respiratory chain contribute to diclofenac-induced mitochondrial dysfunction
}

\section{Correspondence \\ J. Chris Vos \\ JC.Vos@few.vu.nl}

Received 13 August 2010

Revised 3 December 2010

Accepted 7 December 2010

\author{
Jolanda S. van Leeuwen, ${ }^{1}$ Rick Orij, ${ }^{2}$ Marijke A. H. Luttik, ${ }^{3,4}$ \\ Gertien J. Smits, ${ }^{2}$ Nico P. E. Vermeulen ${ }^{1}$ and J. Chris Vos ${ }^{1}$
}

${ }^{1}$ LACDR, Division of Molecular Toxicology, Department of Chemistry and Pharmaceutical Sciences, VU University Amsterdam, De Boelelaan 1083, 1081 HV Amsterdam, The Netherlands

${ }^{2}$ Department of Molecular Biology and Microbial Food Safety, Swammerdam Institute for Life Sciences, University of Amsterdam, Science Park 904, 1098 XH Amsterdam, The Netherlands

${ }^{3}$ Kluyver Centre for Genomics of Industrial Fermentation, Julianalaan 67, 2628 BC Delft, The Netherlands

${ }^{4}$ Department of Biotechnology, Delft University of Technology, Julianalaan 67, 2628 BC Delft, The Netherlands

The widely used drug diclofenac can cause serious heart, liver and kidney injury, which may be related to its ability to cause mitochondrial dysfunction. Using Saccharomyces cerevisiae as a model system, we studied the mechanisms of diclofenac toxicity and the role of mitochondria therein. We found that diclofenac reduced cell growth and viability and increased levels of reactive oxygen species (ROS). Strains increasingly relying on respiration for their energy production showed enhanced sensitivity to diclofenac. Furthermore, oxygen consumption was inhibited by diclofenac, suggesting that the drug inhibits respiration. To identify the site of respiratory inhibition, we investigated the effects of deletion of respiratory chain subunits on diclofenac toxicity. Whereas deletion of most subunits had no effect, loss of either Rip1p of complex III or Cox9p of complex IV resulted in enhanced resistance to diclofenac. In these deletion strains, diclofenac did not increase ROS formation as severely as in the wild-type. Our data are consistent with a mechanism of toxicity in which diclofenac inhibits respiration by interfering with Rip1p and Cox9p in the respiratory chain, resulting in ROS production that causes cell death.

\section{INTRODUCTION}

Diclofenac, a non-steroidal anti-inflammatory drug (NSAID), is widely used in the treatment of diseases involving pain and inflammation, such as arthritis. NSAIDs are inhibitors of prostaglandin synthesis and have been tested as anti-fungal agents, because Candida albicans and Cryptococcus neoformans secrete prostaglandin-like molecules involved in pathogenicity (Alem \& Douglas, 2004; Noverr et al., 2001). In humans, diclofenac causes serious adverse drug reactions that target the liver (Laine et al., 2009), heart (Fosbøl et al., 2009) and upper gastrointestinal tract (Lewis et al., 2002). Mitochondrial dysfunction is increasingly considered a major cause of

\footnotetext{
Abbreviations: CCCP, carbonylcyanide $m$-chlorophenylhydrazone; ETC, electron transport chain; MPT, mitochondrial permeability transition; NSAID, non-steroidal anti-inflammatory drug; PDR, pleiotropic drug resistance; $\mathrm{pH}_{\text {cyt }}$ cytosolic $\mathrm{pH} ; \mathrm{pH}_{\text {mit, }}$ mitochondrial $\mathrm{pH}$; $\mathrm{ROS}$, reactive oxygen species.
}

drug-induced organ failure (Boelsterli \& Lim, 2007; Dykens \& Will, 2007). In mitochondria, electron-donating compounds such as NADH or succinate transfer electrons to the electron transport chain (ETC). The electrons travel through the respiratory chain complexes and are finally donated to oxygen, while protons are pumped across the membrane. This generates a proton motive force consisting of a membrane potential and a $\mathrm{pH}$ gradient that is used by ATPase to produce ATP. Various drugs can interfere with the electron transfer, lowering the mitochondrial membrane potential and decreasing the amount of ATP formed (Labbe et al., 2008). Furthermore, the electrons can leak from the respiratory chain, generating reactive oxygen species (ROS) that can induce apoptosis via the mitochondrial permeability transition (MPT) (Nieminen et al., 1997; Turrens, 2003).

There are several indications of a role for mitochondrial dysfunction in diclofenac toxicity. In rat hepatocytes, diclofenac causes uncoupling of mitochondrial respiration, 
in which oxygen consumption is no longer linked to proton transport over the inner membrane (Masubuchi et al., 2000). This leads to decreased ATP production and ATP depletion (Bort et al., 1999; Masubuchi et al., 2002). Furthermore, in several cellular systems, including human hepatocytes, diclofenac induces ROS formation, causing successive opening of the MPT pore, cytochrome $c$ release, caspase activation and apoptosis (Gómez-Lechón et al., 2003; Inoue et al., 2004; Lim et al., 2006). However, the primary cause of the mitochondrial dysfunction remains unclear.

We used yeast as a model system to elucidate the mechanisms leading to mitochondrial dysfunction in diclofenac toxicity. Baker's yeast (Saccharomyces cerevisiae) is an excellent model organism to study mitochondrial functions, because a detailed knowledge of the composition and assembly of the various respiratory chain complexes can be combined with its genetic tractability. Furthermore, complexes II, III and IV are highly conserved among eukaryotes (Lemire \& Oyedotun, 2002; Taanman \& Capaldi, 1992; Zara et al., 2009). Although yeast lacks complex I, the functional similarity of yeast NADH dehydrogenase Ndilp allows rescue of NADH oxidase activity in complex I-deficient mammalian systems (Seo et al., 1998).

Here, we clearly link diclofenac toxicity to respiration. We demonstrate the unique role of Riplp in complex III and Cox9p in complex IV of the respiratory chain in the toxicity of diclofenac, and show that there is a strong correlation between diclofenac toxicity and the formation of ROS. These results indicate that diclofenac interferes with respiration at the site of Riplp and Cox9p, leading to formation of ROS and cell death.

\section{METHODS}

Chemicals and stock solutions. Diclofenac was purchased as its sodium salt from Sigma Aldrich and dissolved in DMSO (500 mM). $2^{\prime}, 7^{\prime}$-Dichlorofluorescin diacetate was obtained from Alexis Biochemicals and dissolved in ethanol $(4 \mathrm{mM})$. All stock solutions were stored at $-20{ }^{\circ} \mathrm{C}$ and protected from light. All other chemicals were purchased from Sigma Aldrich at the highest purity.

Strains. The haploid BY4741 (MATa; his $3 \Delta 1$; leu2 $\Delta 0$; met $15 \Delta 0$; ura3 $\Delta 0$ ) wild-type and deletion strains were obtained from EUROSCARF. Strains without mitochondrial DNA $\left(\mathrm{rho}^{0}\right)$ were generated by growth with ethidium bromide $\left(10 \mu \mathrm{g} \mathrm{ml}^{-1}\right)$ for several days in rich medium [YPD: $1 \%(\mathrm{w} / \mathrm{v})$ yeast extract, $2 \%(\mathrm{w} / \mathrm{v})$ bactopeptone, $2 \%(\mathrm{w} / \mathrm{v})$ glucose]. Individual colonies were streaked in parallel on YPD and YPEG $[1 \%(\mathrm{w} / \mathrm{v})$ yeast extract, $2 \%(\mathrm{w} / \mathrm{v})$ bactopeptone, $3 \%(\mathrm{v} / \mathrm{v})$ ethanol, $3 \%(\mathrm{v} / \mathrm{v})$ glycerol]. Cells of the rho strain grow only on YPD plates (Goldring et al., 1970). Loss of mitochondrial DNA was confirmed by staining the DNA with $4^{\prime}, 6-$ diamidino-2-phenylindole (DAPI).

Construction of rescue constructs. RIP1 and COX9 genes including 500 bp up- and downstream were amplified by PCR and cloned into YCplac111 (pLEU), a yeast single-copy vector containing the CEN4/ARS1 origin of replication and a LEU2 marker (Gietz \& Sugino, 1988). The plasmids were transformed into the corresponding deletion strains by using the freeze-thaw method (Klebe et al., 1983). Transformed strains were streaked in duplicate on YNB-Leu [0.67\% $(\mathrm{w} / \mathrm{w})$ yeast nitrogen base without amino acids, $2 \%(\mathrm{w} / \mathrm{w})$ glucose, supplemented with amino acids and nucleotides without leucine] and YPEG. The $\Delta \operatorname{cox} 9$ and $\Delta$ rip 1 strains can grow only on YPEG when the deleted gene is complemented by the corresponding rescue construct.

Growth conditions and diclofenac treatment. Strains were grown overnight on minimal medium (YNB) at $30{ }^{\circ} \mathrm{C}$. Overnight cultures were diluted in minimal medium and grown at $30{ }^{\circ} \mathrm{C}$ to $\mathrm{OD}_{600} \sim 0.2$. At this point, $0-100 \mu \mathrm{M}$ diclofenac was added. Controls were treated with equal amounts of DMSO (maximum $0.1 \%, v / v$ ). At various time points, the $\mathrm{OD}_{600}$ of control and diclofenac-treated cultures was measured (Amersham Novaspec II spectrophotometer).

Measurement of cytosolic and mitochondrial $\mathbf{p H}\left(\mathrm{pH}_{\mathrm{cyt}}\right.$ and $\mathbf{p H}_{\text {mit }}$ ). $\mathrm{pH}_{\text {cyt }}$ and $\mathrm{pH}_{\text {mit }}$ were measured as described previously (Orij et al., 2009). Briefly, strains containing a plasmid carrying the pHluorin gene with or without a mitochondrial targeting sequence were grown in black, clear-bottomed 96-well plates in minimal medium buffered at pH 5.0 with $25 \mathrm{mM}$ sodium citrate. Fluorescence $\left(\lambda_{\mathrm{ex}}=390\right.$ or $\left.470 \mathrm{~nm}, \lambda_{\mathrm{em}}=512 \mathrm{~nm}\right)$ was measured and corrected for the cell density in the wells. The ratio of pHluorin emission intensity resulting from excitation at 390 and $470 \mathrm{~nm}$ was calculated and compared with a standard curve to determine the $\mathrm{pH}$.

Oxygen consumption measurements. Oxygen consumption rates of whole cells were determined at $30{ }^{\circ} \mathrm{C}$ with a Clark-type oxygen electrode. The reaction mixture $(4 \mathrm{ml})$ contained $100 \mathrm{mM}$ potassium phosphate buffer ( $\mathrm{pH} 3.0$ or 5.0 ), $10 \mathrm{mM} \mathrm{MgSO}_{4}$ and $\sim 6 \times 10^{6}$ cells. Reactions were started by addition of $0.5 \%(\mathrm{w} / \mathrm{v})$ glucose. After incubating for $2 \mathrm{~min}, 0-200 \mu \mathrm{M}$ diclofenac was added. Oxygenuptake rates were calculated based on a dissolved oxygen concentration of $236 \mu \mathrm{M}$ in air-saturated water at $30{ }^{\circ} \mathrm{C}$.

Survival assay. Exponentially growing cultures of $\mathrm{OD}_{600} \sim 0.2$ were incubated with 0 or $100 \mu \mathrm{M}$ diclofenac. After $6 \mathrm{~h}$, the $\mathrm{OD}_{600}$ was measured and $1 \times 10^{-5}$ OD units ( 300 cells) were plated on YPD plates. After incubation at $30{ }^{\circ} \mathrm{C}$ for 3 days, the number of colonies was counted.

Measurement of ROS production. Exponentially growing cultures ( $2 \mathrm{ml}$ ) of $\mathrm{OD}_{600} \sim 0.2$ were treated with $0-50 \mu \mathrm{M}$ diclofenac in the presence of $10 \mu \mathrm{M}$ of the fluorescent, ROS-sensitive $2^{\prime}, 7^{\prime}$-dichlorofluorescin diacetate. After $3 \mathrm{~h}$ at $30^{\circ} \mathrm{C}$ the cultures were centrifuged ( 3 min at 3000 r.p.m.), and cell pellets were washed and resuspended in $1 \mathrm{ml}$ water. Fluorescence $\left(\lambda_{\mathrm{ex}}=485 \mathrm{~nm}, \lambda_{\mathrm{em}}=535 \mathrm{~nm}\right)$ was measured and corrected for the cell density in the samples.

$\boldsymbol{\beta}$-Galactosidase reporter assay. The PDR3- and PDR5-lacZ reporter constructs in the low-copy-number vector pSEYC102 were a kind gift from Professor Scott Moye-Rowley, University of Iowa, Iowa City, IA, USA (Katzmann et al., 1994). The plasmids were transformed into yeast by using the freeze-thaw method (Klebe et al., 1983). Yeast cultures were grown at $30{ }^{\circ} \mathrm{C}$ to $\mathrm{OD}_{600} \sim 0.5$. Protein extracts were made in LacZ buffer $\left(40 \mathrm{mM} \mathrm{Na}_{2} \mathrm{HPO}_{4}, 60 \mathrm{mM} \mathrm{NaH} \mathrm{PO}_{4}, 10 \mathrm{mM} \mathrm{KCl}, 1 \mathrm{mM} \mathrm{MgSO}\right.$, $50 \mathrm{mM} \beta$-mercaptoethanol) by using glass beads. Then, $5-35 \mu \mathrm{g}$ protein was incubated with $24 \mu \mathrm{g}$ chlorophenol red- $\beta$-D-galactopyranoside at $30{ }^{\circ} \mathrm{C}$ for $10-360 \mathrm{~min} . A_{575}$ was measured and corrected for the protein concentration in the samples and incubation time.

\section{RESULTS}

\section{Respiring yeast cells show increased sensitivity to diclofenac}

Previous studies in mammalian cells show that mitochondria play a role in diclofenac toxicity (Gómez-Lechón et al., 2003; Inoue et al., 2004; Lim et al., 2006; Masubuchi et al., 2002). To 
investigate whether diclofenac interferes with mitochondrial respiration in S. cerevisiae, we studied the effect of various carbon sources on the sensitivity of wild-type cells to diclofenac. Growth of the cultures was monitored on medium containing glucose or galactose as carbon source supplemented with 0,50 or $100 \mu \mathrm{M}$ diclofenac (Fig. 1). When yeast is grown on glucose, the cells derive most of their energy from glycolysis. With galactose as carbon source, cells are more reliant on respiration (Fendt \& Sauer, 2010). On glucose, cells treated with $50 \mu \mathrm{M}$ diclofenac grew significantly more slowly than untreated cells (Fig. 1a). However, on galactose, cells grew even more slowly after treatment with $50 \mu \mathrm{M}$ diclofenac (Fig. 1b). Clearly, when cells are increasingly dependent on respiration, diclofenac toxicity is enhanced. During incubation with $100 \mu \mathrm{M}$ diclofenac in either glucose or galactose, cells barely grew at all.

To confirm that respiration increases diclofenac toxicity, we tested the diclofenac sensitivity of strains lacking mitochondrial DNA $\left(\mathrm{rho}^{0}\right)$. Cells of the rho ${ }^{0}$ strains are deficient in respiration but can grow on fermentable carbon sources such as glucose, although more slowly than wild-type cells. Whereas wild-type cells hardly grew on $100 \mu \mathrm{M}$ diclofenac, this diclofenac concentration had only a minor effect on the growth of rho ${ }^{0}$ cells (Fig. 1c), confirming the importance of respiration in diclofenac toxicity.

\section{Diclofenac inhibits respiration but does not dissipate the proton gradient over the mitochondrial membrane}

One of the current hypotheses regarding diclofenac toxicity is that it uncouples oxygen consumption from ATP production by dissipating the proton gradient (Masubuchi et al., 2002). We used the $\mathrm{pH}$-sensitive green fluorescent protein pHluorin (Orij et al., 2009) to measure $\mathrm{pH}_{\text {cyt }}$ and $\mathrm{pH}_{\text {mit }}$. To rule out influences of external $\mathrm{pH}$, cells were grown in medium buffered at $\mathrm{pH} 5$. In this buffered medium, $200 \mu \mathrm{M}$ diclofenac has similar effects on cell death and growth as $50 \mu \mathrm{M}$ diclofenac in non-buffered medium (data not shown). As diclofenac is a weak acid ( $\left.\mathrm{p} K_{\mathrm{a}} \sim 4.0\right)$, its uptake is higher in the more acidic non-buffered medium (Wohnsland \& Faller, 2001), leading to increased toxicity.

Wild-type cells were grown in glucose-containing media and fluorescence was monitored. The exponentially growing cells had a $\mathrm{pH}_{\text {cyt }}$ of 6.9 and a $\mathrm{pH}_{\text {mit }}$ of 7.2. After addition of $200 \mu \mathrm{M}$ diclofenac, both values decreased quickly (Fig. 2a). After $30 \mathrm{~min}$, the $\mathrm{pH}$ stabilized at 6.4 in the cytosol and 6.6 in the mitochondria and remained constant for at least $6 \mathrm{~h}$ (data not shown). Previously, the uncoupler carbonylcyanide $m$-chlorophenylhydrazone (CCCP) was shown to diminish the difference between $\mathrm{pH}_{\text {cyt }}$ and $\mathrm{pH}_{\text {mit }}$ (Orij et al., 2009). As the difference between mitochondrial and cytosolic $\mathrm{pH}$ remained intact with diclofenac, we conclude that diclofenac does not uncouple respiration.

As diclofenac is more toxic to respiring than to fermenting cells, we examined whether it inhibits respiration in yeast. Wild-type cells were incubated in potassium phosphate buffer at $\mathrm{pH} 3.0$ or 5.0 and oxygen consumption was measured in the presence of glucose and $0-200 \mu \mathrm{M}$ diclofenac (Fig. 2b). Oxygen consumption in the absence of diclofenac was comparable at both $\mathrm{pHs}(\sim 7.4$ fmol $\min ^{-1}$ per cell) and was set at $100 \%$. Diclofenac dose-dependently inhibited respiration at both $\mathrm{pH} 3.0$ and 5.0. However, at $\mathrm{pH} 3.0$ the inhibition was more severe. At $\mathrm{pH}$ 5.0, $200 \mu \mathrm{M}$ diclofenac inhibited respiration by $\sim 13 \%$, which is comparable with the inhibition by $50 \mu \mathrm{M}$ diclofenac at $\mathrm{pH}$ 3.0. Because growth inhibition under these two conditions is comparable, there is a clear correlation between growth inhibition and reduced oxygen consumption at both pHs. Together, these results show that diclofenac inhibits, but does not uncouple, respiration.

\section{Diclofenac induces the formation of ROS in wild- type but not in rho $^{\circ}$ strains}

As the respiratory chain is the main source of ROS in the mitochondria, we tested the effect of respiration on diclofenac-induced ROS formation. Wild-type and rho ${ }^{\circ}$
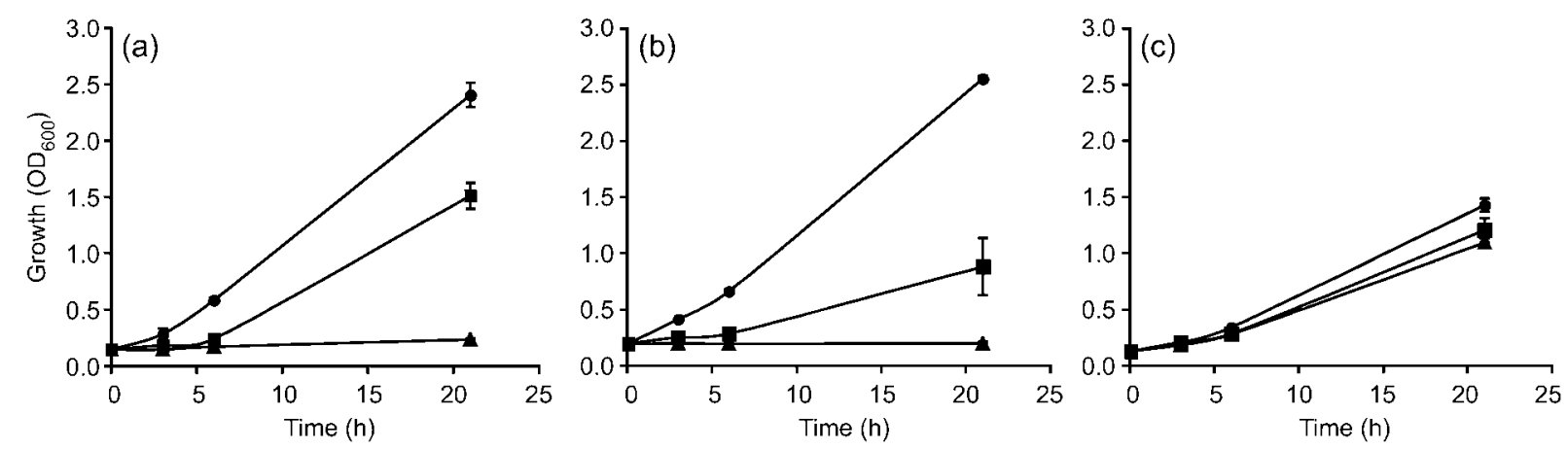

Fig. 1. Respiring cells are more sensitive to diclofenac. The wild-type yeast strain grown on (a) glucose or (b) galactose as carbon source and (c) a strain without mitochondrial DNA $\left(\mathrm{rho}^{\circ}\right)$ grown on glucose were incubated with $0 \mu \mathrm{M}(\mathbf{0}), 50 \mu \mathrm{M}(\boldsymbol{\square})$ or $100 \mu \mathrm{M}(\mathbf{A})$ diclofenac. Growth is expressed as $\mathrm{OD}_{600}$ (mean $\pm \mathrm{SD}$ ). Experiments were performed three times using independently generated rho $^{\circ}$ strains. 
(a)

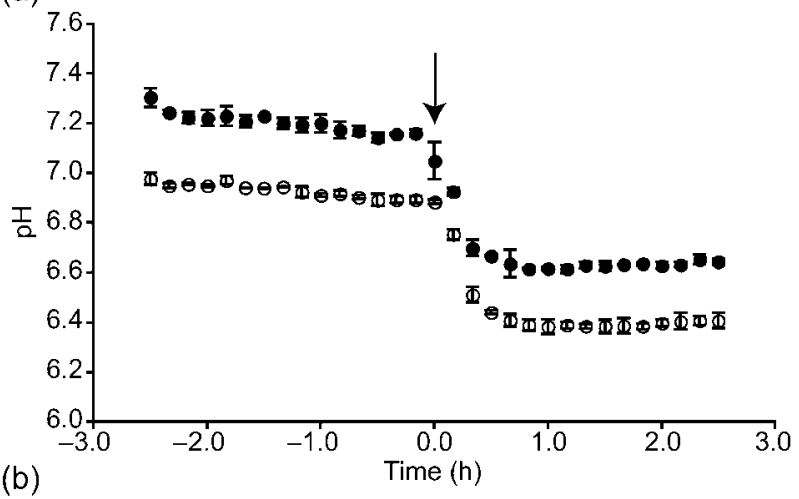

(b)

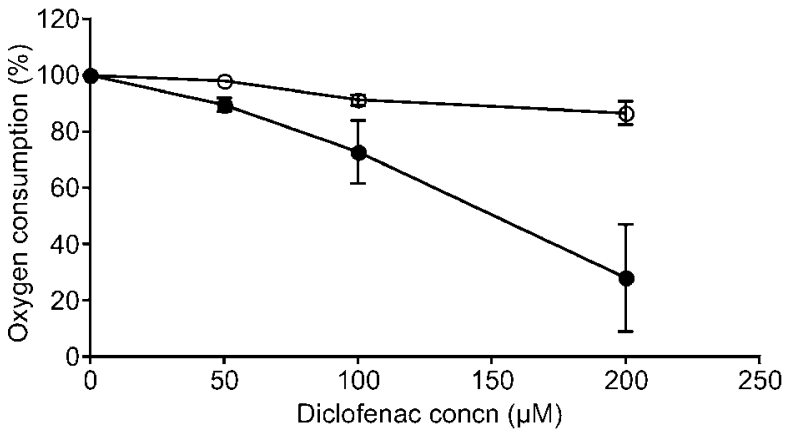

Fig. 2. Diclofenac inhibits oxygen consumption but does not influence the proton gradient. (a) Wild-type cells were grown in minimal media buffered at $\mathrm{pH}$ 5.0. $\mathrm{pH}_{\text {cyt }}(\bigcirc)$ and $\mathrm{pH}_{\text {mit }}(\bullet)$ were measured by using the $\mathrm{pH}$-dependent fluorescent protein pHluorin. Fluorescence was corrected for cell density. At $t=0$ (arrow), $200 \mu \mathrm{M}$ diclofenac was added. Data are expressed as mean \pm SD $(n=3)$. (b) Oxygen consumption was measured in wildtype cells incubated at $\mathrm{pH} 3.0(\bigcirc)$ or $\mathrm{pH} 5.0(0)$ with 0-200 $\mu \mathrm{M}$ diclofenac. Data are expressed as percentage oxygen consumption compared with cells incubated without diclofenac (100\%) (mean $\pm \mathrm{SD}, n=3$ ).

strains were incubated for $3 \mathrm{~h}$ in the presence of the ROSsensitive fluorescent compound $2^{\prime}, 7^{\prime}$-dichlorofluorescin diacetate and $0,10,30$ or $50 \mu \mathrm{M}$ diclofenac. ROS levels in the absence of diclofenac were set at $100 \%$. In wild-type cells, diclofenac dose-dependently increased the amount of ROS formed (Fig. 3). Even at diclofenac concentrations of $30 \mu \mathrm{M}$ the amount of ROS in the cells was doubled compared with wild-type cells incubated without diclofenac. At $50 \mu \mathrm{M}$ diclofenac, cellular ROS levels were $\sim 3.5$-fold higher than in the untreated control cells. In contrast, these diclofenac concentrations did not induce ROS formation in the respiratory-deficient rho ${ }^{0}$ strain (Fig. 3) compared with rho ${ }^{0}$ controls. These results show a relationship between respiration, ROS formation and diclofenac toxicity.

\section{Crucial role of respiratory chain subunits Rip1p and Cox9p in the toxicity of diclofenac}

To investigate the role of mitochondrial respiration in diclofenac toxicity in more detail, we tested the effect of individual respiratory chain proteins on diclofenac toxicity. Single gene deletion strains were used in which non-essential, nuclear-encoded subunits of the respiratory chain complexes were deleted. The deletion strains were grown for $6 \mathrm{~h}$ in the presence of 0 or $100 \mu \mathrm{M}$ diclofenac. For each strain, the growth (increase in $\mathrm{OD}_{600}$ in $6 \mathrm{~h}$ ) of cultures incubated without diclofenac was set at $100 \%$ and the percentage growth of diclofenac-treated cultures was calculated (Fig. 4a).

Growth of wild-type cultures incubated with $100 \mu \mathrm{M}$ diclofenac was only $\sim 5 \%$ of that of control cultures. As also seen in Fig. 1, the rho ${ }^{0}$ strain was much more resistant to diclofenac, with $\sim 80 \%$ growth compared with untreated cells. Deletion of the complex I homologue Ndilp or subunits of complex II did not significantly change the sensitivity to diclofenac compared with wild-type cells. However, deletion of subunit Riplp ( $\Delta$ rip1) of complex III increased the resistance to diclofenac, with $\sim 40 \%$ growth compared with control cells. Interestingly, deletion of subunit $\operatorname{Cox} 9 \mathrm{p}(\Delta \operatorname{cox} 9)$ of complex IV also increased diclofenac resistance.

The viability of the deletion strains after incubating for $6 \mathrm{~h}$ with $100 \mu \mathrm{M}$ diclofenac was also analysed. The results (Fig. $4 \mathrm{~b})$ correlate with those of the growth assay. Only $\sim 5 \%$ of the wild-type cells survived the diclofenac treatment. The rho $^{\circ}, \Delta$ ripl and $\Delta \operatorname{cox} 9$ strains showed strongly increased resistance to diclofenac, with $\sim 85, \sim 55$ and $\sim 65 \%$ of the cells surviving diclofenac treatment, respectively. Deletion of other complex III or IV subunits had some effect on diclofenac toxicity; in particular, the $\Delta$ cyt1 and $\Delta \operatorname{cox} 7$ strains showed slightly increased diclofenac resistance in the growth and survival assays.

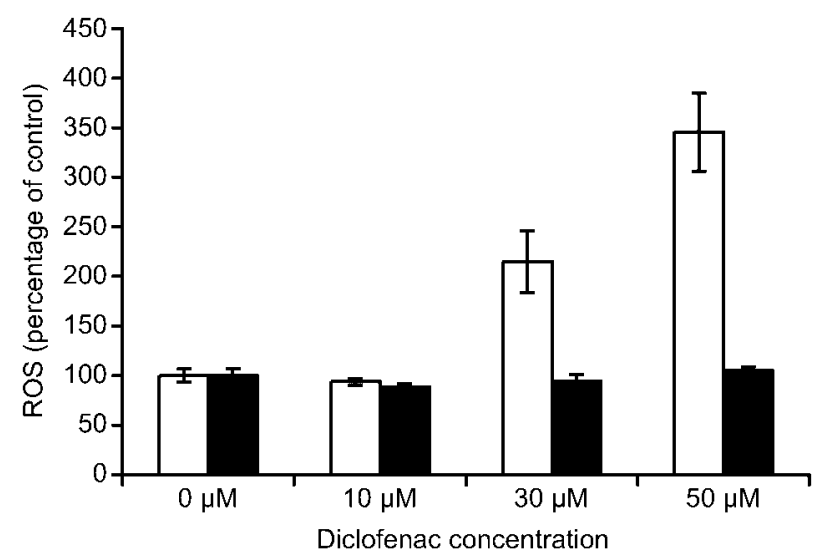

Fig. 3. Diclofenac increases ROS levels in wild-type but not in rho $^{\circ}$ cells. The wild-type yeast strain (open bars) and a strain lacking mitochondrial DNA (rho ${ }^{\circ}$, closed bars) were grown in the presence of $0,10,30$ or $50 \mu \mathrm{M}$ diclofenac. After $3 \mathrm{~h}$, ROS levels were measured by using the fluorescent ROS marker $2^{\prime}, 7^{\prime}$ dichlorofluorescin diacetate. Measured fluorescence is corrected for cell density. ROS formation is expressed as percentage fluorescence compared with wild-type or $\mathrm{rho}^{\circ}$ controls incubated without diclofenac $(100 \%)$ (mean $\pm \mathrm{SD})$. Experiments were performed three times by using independently generated rho $^{0}$ strains. 


\section{(a)}

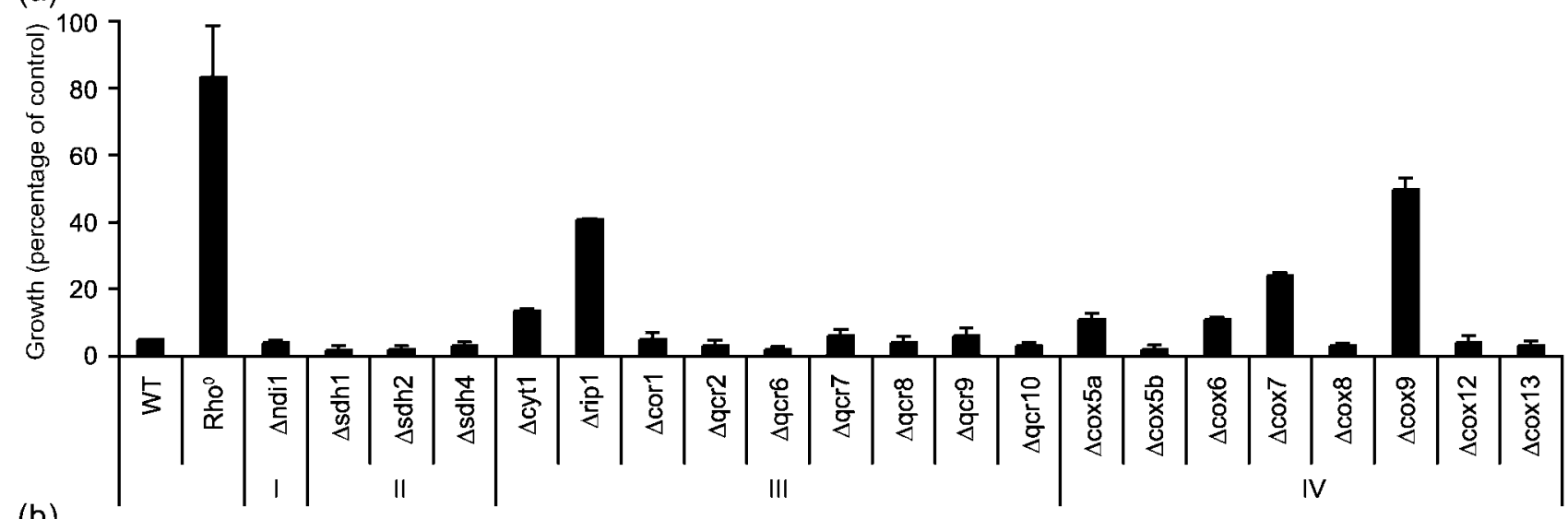

(b)

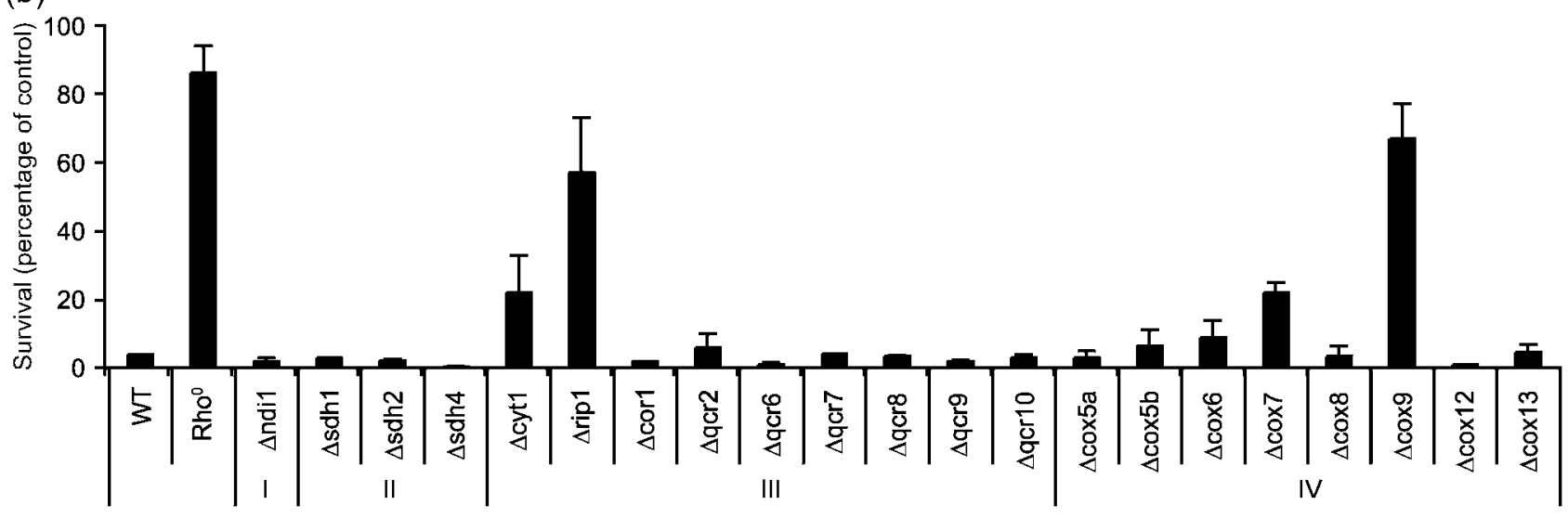

Fig. 4. Diclofenac toxicity is dependent on Rip1p and Cox9p. Growth (a) and survival (b) after incubation with $100 \mu \mathrm{M}$ diclofenac for $6 \mathrm{~h}$ of the wild-type strain (WT), a strain lacking mitochondrial DNA (Rho ${ }^{\circ}$ ) and strains in which a subunit of respiratory chain complex I, II, III or IV was deleted. Data are expressed as percentage growth $\left(\mathrm{OD}_{600}\right)$ or percentage surviving cells compared with cells of the same strain incubated without diclofenac (100\%). Data represent means and SDs of two independent experiments performed in duplicate.

\section{Complementation of the deleted genes restores diclofenac sensitivity}

To confirm that the diclofenac resistance observed in the $\Delta$ rip 1 and $\Delta \operatorname{cox} 9$ deletion strains was solely due to absence of the RIP1 and COX9 genes, we introduced plasmid-based copies of the genes into the corresponding deletion strains. The RIP1 and COX9 genes were under the control of their own promoter. Successful complementation of the deleted gene should restore the ability to respire and result in a diclofenac-sensitive wild-type phenotype.

Wild-type, $\Delta$ rip 1 and $\Delta \operatorname{cox} 9$ strains transformed with an empty vector (pLEU), and the complemented strains $\Delta$ rip $1+$ pLEU-RIP1 and $\Delta \operatorname{cox} 9+$ pLEU-COX9, were streaked in parallel on plates containing glucose (Fig. 5a) or ethanol and glycerol (Fig. 5b) as carbon source. All strains were able to grow on plates containing glucose. Whereas the $\Delta$ rip 1 and $\Delta \operatorname{cox} 9$ strains transformed with an empty vector were unable to grow on plates containing the non-fermentable carbon sources ethanol and glycerol, the complemented $\Delta$ rip $1+$ pLEU-RIP1 and $\Delta \operatorname{cox} 9+$ pLEUCOX9 strains grew on these plates. This shows that the ability to respire was restored in the complemented strains.

We also tested the effect of diclofenac on the growth of the strains. For each strain, growth without diclofenac was set at $100 \%$. Whereas the $\Delta$ rip 1 and $\Delta \operatorname{cox} 9$ strains were resistant to diclofenac, the $\Delta$ rip 1 and $\Delta \operatorname{cox} 9$ strains transformed with the pLEU-RIP1 and pLEU-COX9 constructs, respectively, were sensitive to diclofenac (Fig. 5c), confirming that Rip1p and Cox9p are involved in diclofenac toxicity.

\section{Retrograde upregulation of the pleiotropic drug resistance (PDR) response is not involved in diclofenac resistance of complex III and IV deletion strains}

In rho ${ }^{0}$ cells and in strains lacking certain complex $\mathrm{V}$ subunits, several genes involved in PDR, including multidrug transporter PDR5 and transcription factor $P D R 3$, are 

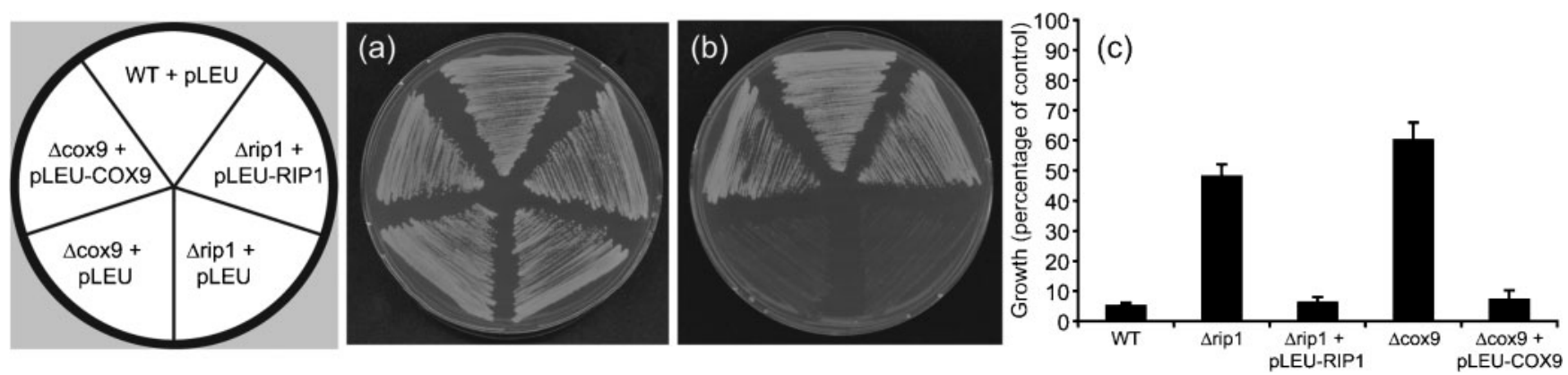

Fig. 5. Complementation of the deleted genes restores respiration and diclofenac sensitivity in $\Delta$ rip 1 and $\Delta \operatorname{cox} 9$ strains. The $\Delta$ rip1 and $\Delta \operatorname{cox} 9$ deletion strains were transformed with constructs containing the RIP1 and COX9 genes under the control of their own promoter. Wild-type (WT), $\Delta$ rip1 and $\Delta$ cox9 strains transformed with an empty vector (pLEU) and the complemented $\Delta$ rip $1+$ pLEU-RIP1 and $\Delta$ cox9 + pLEU-COX9 were grown on plates containing (a) glucose (YPD) or (b) ethanol and glycerol (YPEG) as carbon source. Only strains that are able to respire can grow on YPEG plates. (c) Wild-type (WT), $\Delta$ rip1, $\Delta$ cox9 and the complemented $\Delta$ rip $1+$ pLEU-RIP1 and $\Delta \operatorname{cox} 9+$ pLEU-COX9 strains were grown in the presence of $100 \mu \mathrm{M}$ diclofenac. Data are expressed as percentage growth $\left(\mathrm{OD}_{600}\right)$ after $6 \mathrm{~h}$ compared with cells of the same strain incubated without diclofenac. Data represent means and SDS of two independent experiments performed in duplicate using different transformants.

upregulated compared with wild-type cells (Hallstrom \& Moye-Rowley, 2000; Zhang \& Moye-Rowley, 2001). Deletion of complex III or IV subunits may also cause upregulation of the PDR genes, which can affect diclofenac resistance. Therefore, we examined PDR3 and PDR5 expression in the diclofenac-resistant $\Delta$ rip 1 and $\Delta \operatorname{cox} 9$ strains. By using a $\beta$ galactosidase reporter assay, we measured PDR3 and PDR5 promoter activity. For both genes an increase in lac $Z$ expression was observed in the rho ${ }^{0}$ strain (Table 1), as reported by Hallstrom \& Moye-Rowley (2000). In the $\Delta$ rip1 and $\Delta \operatorname{cox} 9$ strains, lac $Z$ expression for both genes was similar to that in the wild-type. This indicates that diclofenac resistance in these deletion strains is not caused by an upregulation of the multidrug resistance genes.

\section{Diclofenac sensitivity correlates with the formation of ROS}

To explore further why deletion of Rip $1 p$ and Cox9p resulted in diclofenac resistance, whereas deletion of other complex III or IV subunits did not, we investigated whether the deletion of these genes had an effect on the amount of ROS in the cell. First, we investigated ROS levels in the wild-type and deletion strains grown in the absence of diclofenac to compare basal ROS levels. The strains were grown for $3 \mathrm{~h}$ in the presence of the ROS marker $2^{\prime}, 7^{\prime}$ dichlorofluorescin diacetate. No significant differences in basal ROS levels were observed (Fig. 6a).

Second, we tested ROS levels after incubation with $50 \mu \mathrm{M}$ diclofenac and $2^{\prime}, 7^{\prime}$-dichlorofluorescin diacetate for $3 \mathrm{~h}$ (Fig. 6b). In almost all deletion strains, ROS formation was increased approximately fourfold upon diclofenac treatment compared with ROS levels in the same strain incubated without diclofenac. Apparently, the disruption of stable complex III or IV formation does not decrease the potential of diclofenac to increase ROS formation. However, in the diclofenac-resistant $\Delta$ rip 1 and $\Delta \operatorname{cox} 9$ strains, ROS levels were only $\sim 200$ and $\sim 150 \%$ of untreated controls, respectively. These results show a

Table 1. Multidrug resistance genes $P D R 3$ and $P D R 5$ are not upregulated in $\Delta$ rip 1 and $\Delta \operatorname{cox} 9$ strains

PDR3-lacZ and PDR5-lacZ expression in the wild-type strain, a strain lacking mitochondrial DNA $\left(\mathrm{Rho}^{\circ}\right)$ and strains in which either subunit Rip1p or Cox9p of the respiratory chain was deleted. Data are expressed as units of $\beta$-galactosidase activity, corrected for the protein concentration and incubation time. Data are means \pm SD of two experiments performed in duplicate using different transformants.

\begin{tabular}{|lcr|}
\hline Strain & $\boldsymbol{\beta}$-Galactosidase activity $\left(\mathbf{u n i t s}_{\boldsymbol{\mu}} \mathbf{g}^{\mathbf{- 1}} \mathbf{~ m i n}^{-\mathbf{1}}\right.$ ) \\
\cline { 2 - 3 } & PDR3-lacZ & PDR5-lacZ \\
\hline Wild-type & $1.7 \pm 0.3$ & $77 \pm 11$ \\
Rho $^{0}$ & $3.4 \pm 0.4$ & $213 \pm 22$ \\
$\Delta$ rip1 & $2.1 \pm 0.1$ & $87 \pm 27$ \\
$\Delta$ cox9 & $1.8 \pm 0.2$ & $90 \pm 21$ \\
\hline
\end{tabular}


strong correlation between diclofenac toxicity and ROS formation, and the unique roles of Riplp and Cox9p within the ETC.

\section{DISCUSSION}

One of the challenges in examining the toxicity of drugs is identifying the cellular target(s). Yeast cells are useful in the identification of genes important in drug toxicity (Bharucha \& Kumar, 2007). An advantage of yeast over mammalian cellular systems is the relatively straightforward way of performing genetic modifications. Here, we used yeast to study the mitochondrial toxicity of diclofenac.

In several cellular systems, including human hepatocytes, diclofenac can induce ROS formation that causes successive opening of the MPT pore, cytochrome $c$ release, caspase activation and apoptosis (Gómez-Lechón et al., 2003; Inoue et al., 2004; Lim et al., 2006). As the respiratory chain is a well-known source of ROS (Kowaltowski et al., 2009; Poyton et al., 2009), we studied the role of respiration in diclofenac-induced ROS formation. We showed that when cells are increasingly dependent on respiration, diclofenac toxicity is enhanced (Fig. 1). Strains that lack mitochondrial DNA $\left(\mathrm{rho}^{0}\right)$ are deficient in respiration and show an increased resistance to diclofenac (Fig. 1). Furthermore, loss of mtDNA completely diminished diclofenac-induced ROS formation (Fig. 3). These results indicate a clear link between mitochondrial respiration, ROS formation and diclofenac toxicity. Interestingly, another NSAID, aspirin, has also been linked to mitochondrial dysfunction in yeast, leading to apoptosis (Sapienza et al., 2008).

Most of the oxygen consumed by yeast is used by the respiratory chain (reviewed by Rosenfeld \& Beauvoit,
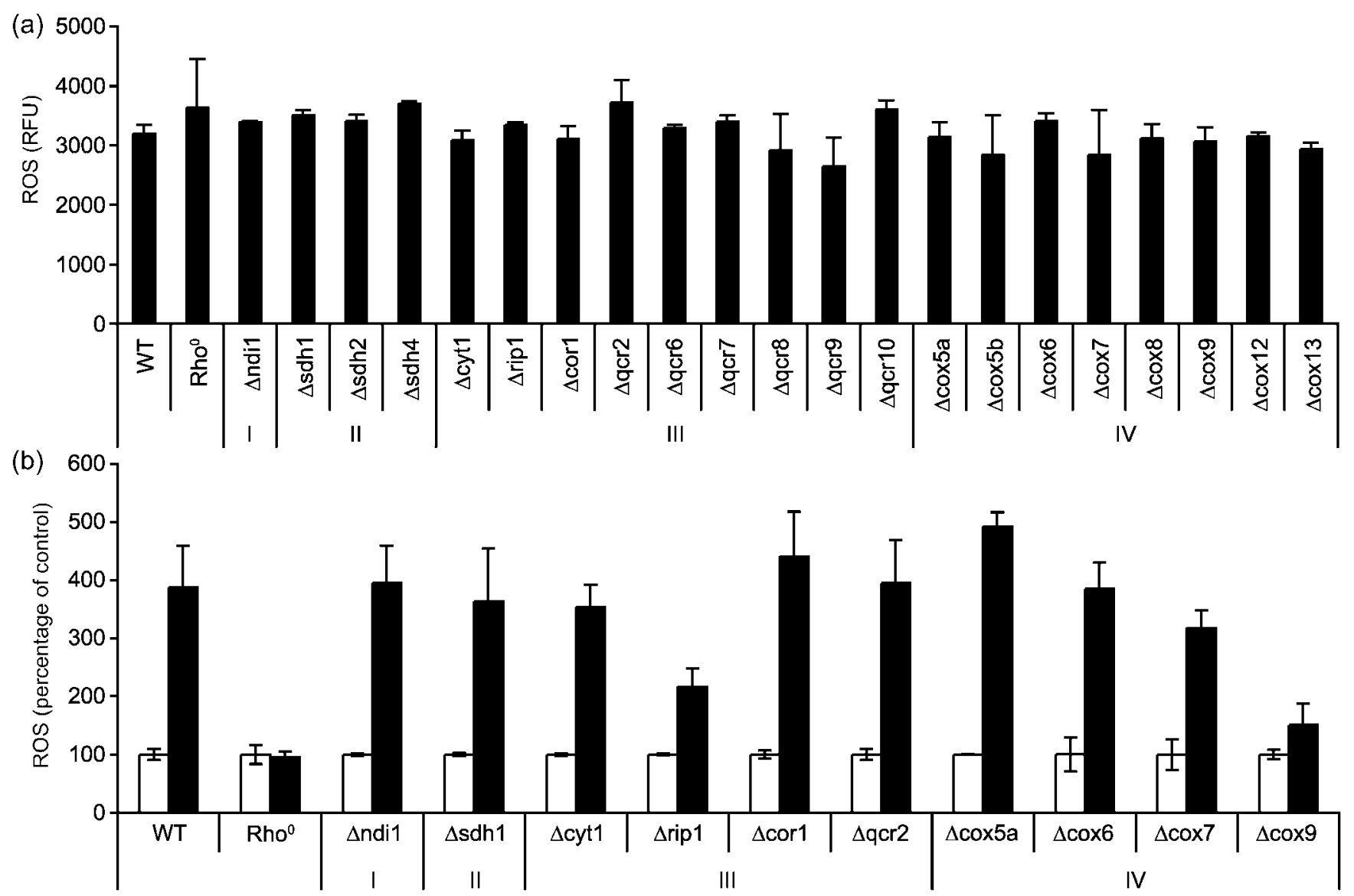

Fig. 6. Diclofenac resistance is correlated with ROS formation. (a) Basal ROS levels in the wild-type (WT), a strain lacking mitochondrial DNA $\left(\mathrm{Rho}^{\circ}\right)$ and strains in which a subunit of respiratory chain complex I, II, III or IV was deleted. For this experiment the strains were not incubated with diclofenac. (b) ROS formation after $3 \mathrm{~h}$ of incubation without (open bars) or with $50 \mu \mathrm{M}$ diclofenac (closed bars) in the wild-type (WT), a strain lacking mitochondrial DNA $\left(\mathrm{rho}^{\circ}\right)$ and strains in which a subunit of respiratory chain complex I, II, III or IV was deleted. ROS formation was measured by using the fluorescent ROS marker $2^{\prime}, 7^{\prime}-$ dichlorofluorescin diacetate. Fluorescence is corrected for cell density and expressed as units (relative fluorescence units; RFU) or as a percentage compared with cells of the same strain incubated without diclofenac. Values are mean $\pm \operatorname{SD}(n=4)$. 
2003). Respiratory inhibitors can almost fully inhibit oxygen consumption. Here, we show that diclofenac can also inhibit oxygen consumption in yeast. Inhibition of oxygen consumption by diclofenac was also found in mammalian cells (Niklas et al., 2009; Krause et al., 2003). Uncoupling of respiration by diclofenac is thought to be responsible for mitochondrial dysfunction. Although a collapse of the mitochondrial membrane potential after diclofenac exposure has been described in mammalian cells (Bort et al., 1999; Inoue et al., 2004; Lim et al., 2006; Masubuchi et al., 2002), this can also be the result of opening of the MPT pore instead of uncoupling. Here, we followed the effect of diclofenac on $\mathrm{pH}_{\text {cyt }}$ and $\mathrm{pH}_{\text {mit }}$ over time. We observed an immediate decrease in both $\mathrm{pH}_{\mathrm{cyt}}$ and $\mathrm{pH}_{\text {mit }}$, but the difference between the two values remained intact. Similar results have been described for the complex III inhibitor antimycin A, while the uncoupler CCCP does lead to dissipation of the $\mathrm{pH}$ difference (Orij et al., 2009). This indicates that under these experimental conditions, diclofenac does not uncouple respiration or induce MPT pore opening in yeast.

Using single gene deletion mutants, we identified Rip1p and Cox9p of complex III and IV, respectively, as possible targets of diclofenac in the respiratory chain. Deletion of Riplp or Cox9p markedly increased growth and survival during diclofenac treatment compared with wild-type and other deletion strains (Fig. 4). Furthermore, $\Delta$ rip1 and $\Delta \operatorname{cox} 9$ strains had markedly lower ROS levels during diclofenac incubation than the wild-type strain (Fig. 6b). To determine ROS formation we used $2^{\prime}, 7^{\prime}$-dichlorofluorescin diacetate. However, as this probe is slightly $\mathrm{pH}-$ sensitive we repeated the ROS assay for wild-type, $\Delta$ rip1 and $\Delta \operatorname{cox} 9$ strains with another ROS-sensitive probe, dihydroethidium, and obtained similar results (data not shown). This strong correlation between ROS levels and diclofenac sensitivity indicates that the formation of ROS is the main cause of toxicity. The mitochondrial superoxide dismutase SOD2 has been suggested to be a diclofenac target in neuroblastoma cells, as evidenced by reduced levels of SOD2 protein and activity upon diclofenac exposure (Cecere et al., 2010). Therefore, we tested deletion mutants of SOD1 and SOD2 in yeast, but did not observe a reduced diclofenac sensitivity compared with the wild-type over $21 \mathrm{~h}$ of incubation.

We confirmed the role of Riplp and Cox9p in diclofenac toxicity by showing that complementation of the genes in the deletion strains restores the diclofenac-sensitive phenotype. Although the diclofenac resistance of $\Delta$ rip1 and $\Delta \operatorname{cox} 9$ strains was significantly increased compared with wild-type cells, they were not as resistant as the rho ${ }^{0}$ strain. The higher diclofenac resistance of the rho ${ }^{0}$ cells can be explained as an additional effect of lacking both complex III and complex IV activity. Furthermore, upregulation of the PDR multidrug response in rho ${ }^{0}$ cells (Table 1) (Hallstrom \& Moye-Rowley, 2000) may contribute to the resistance. For other NSAIDs such as acetaminophen (Srikanth et al., 2005) and indomethacin (Mima et al.,
2007), a role for $A B C$ transporters in their toxicity towards $S$. cerevisiae has been shown.

Rip1p, a Rieske iron-sulfur protein, is one of the catalytic subunits of complex III. Complex III has two distinct binding sites for ubiquinone: the Qi site and the Qo site. The Qo site consists of the proximal niche close to the haem bL of the mitochondrially encoded cytochrome B (Cobp) and the distal niche close to the iron-sulfur cluster of Riplp. In particular, complex III inhibitors that bind in the proximal Qo niche or at the Qi site induce ROS formation by inhibiting electron transport (Muller et al., 2003; Yang et al., 2008). It is tempting to speculate that diclofenac can bind at one of these sites, thereby inhibiting respiration and inducing leakage of electrons. In the absence of Riplp, the ability of diclofenac to generate ROS is lost. Loss of the iron-sulfur protein also abolishes the increase in hypoxia- or methyl mercury-induced ROS (Guzy et al., 2007; Lee et al., 2009). Furthermore, inhibition of Riplp mobility by stigmatellin decreases both basal and induced ROS formation (Armstrong et al., 2004; Muller et al., 2003). This indicates that Rip1p is crucial for ROS formation at complex III. Also, loss of Cytlp slightly increased diclofenac resistance, which might be explained by the direct interaction of Cytlp with Riplp. Interestingly, RIP1 is highly conserved across eukaryotes (Beckmann et al., 1989), and downregulation of the mammalian homologue of Riplp, RISP (UQCRFS1), has also been shown to reduce ROS production (Guzy et al., 2005).

Cox9p is a small $(7 \mathrm{kDa})$ protein that is essential for complex IV activity (Wright et al., 1986). In the literature, the protein encoded by COX9 is also referred to as subunit VIIa, whereas the gene product of COX12 is sometimes named Cox9p. Here, we use the nomenclature of the Saccharomyces Genome Database (http://www.yeastgenome. org) and refer to Cox9p as the gene product of COX9. We show that lack of subunit Cox9p lowers diclofenacinduced ROS formation. Cox9p has been suggested to play a role in complex IV assembly or stability (McEwen et al., 1986). Possibly, interactions of diclofenac with Cox9p interfere with complex IV integrity, leading to ROS formation. Interestingly, complex IV has rarely been associated with ROS formation in the literature. As complexes III and IV assemble in a supercomplex, lack of Cox9p might influence electron transfer between the complexes, leading to ROS formation at complex III.

Surprisingly, deletion of several complex III and IV subunits (e.g. Corlp and Cox6p) has been reported to cause loss of Rip1p and Cox9p from the complexes (Calder \& McEwen, 1991; Crivellone et al., 1988; Dowhan et al., 1985) but does not result in diclofenac resistance or reduced ROS formation (Figs 4 and 6b). Perhaps in these cases, subcomplexes of complex III or complex IV are formed that are not stable enough for isolation and are therefore not detected.

In conclusion, we have demonstrated that subunits Riplp of respiratory chain complex III and Cox9p of complex IV 
are crucial to the mitochondrial toxicity of diclofenac. Further research is needed to see whether the mammalian counterparts UQCRFS1 and COX6c (Lenaz \& Genova, 2010) are related to diclofenac toxicity in mammalian cells and to understand how the two proteins dictate diclofenac interference at the ETC.

\section{ACKNOWLEDGEMENTS}

We thank Scott Moye-Rowley, University of Iowa, Iowa City, IA, USA, for the lacZ reporter constructs, Fred van Leeuwen, Netherlands Cancer Institute, Amsterdam, The Netherlands, for yeast strains, Jack Pronk for useful discussions, and Marco Siderius and Jan Commandeur for critically reading the manuscript.

\section{REFERENCES}

Alem, M. A. S. \& Douglas, L. J. (2004). Effects of aspirin and other nonsteroidal anti-inflammatory drugs on biofilms and planktonic cells of Candida albicans. Antimicrob Agents Chemother 48, 41-47.

Armstrong, J. S., Yang, H. Y., Duan, W. \& Whiteman, M. (2004). Cytochrome $b c_{1}$ regulates the mitochondrial permeability transition by two distinct pathways. J Biol Chem 279, 50420-50428.

Beckmann, J. D., Ljungdahl, P. O. \& Trumpower, B. L. (1989), Mutational analysis of the mitochondrial Rieske Iron-Sulfur protein of Saccharomyces cerevisiae. 1. Construction of a RIP1 deletion strain and isolation of temperature-sensitive mutants. J Biol Chem 264, 3713-3722.

Bharucha, N. \& Kumar, A. (2007). Yeast genomics and drug target identification. Comb Chem High Throughput Screen 10, 618-634.

Boelsterli, U. A. \& Lim, P. L. (2007). Mitochondrial abnormalities - a link to idiosyncratic drug hepatotoxicity? Toxicol Appl Pharmacol 220, 92-107.

Bort, R., Ponsoda, X., Jover, R., Gómez-Lechón, M. J. \& Castell, J. V. (1999). Diclofenac toxicity to hepatocytes: a role for drug metabolism in cell toxicity. J Pharmacol Exp Ther 288, 65-72.

Calder, K. M. \& McEwen, J. E. (1991). Deletion of the COX7 gene in Saccharomyces cerevisiae reveals a role for cytochrome $c$ oxidase subunit VII in assembly of remaining subunits. Mol Microbiol 5, 1769-1777.

Cecere, F., luliano, A., Albano, F., Zappelli, C., Castellano, I., Grimaldi, P., Masullo, M., De Vendittis, E. \& Ruocco, M. R. (2010). Diclofenac-induced apoptosis in the neuroblastoma cell line $\mathrm{SH}$ SY5Y: possible involvement of the mitochondrial superoxide dismutase. J Biomed Biotechnol 2010, 801726.

Crivellone, M. D., Wu, M. A. \& Tzagoloff, A. (1988). Assembly of the mitochondrial membrane system. Analysis of structural mutants of the yeast coenzyme $\mathrm{QH}_{2}$-cytochrome $c$ reductase complex. J Biol Chem 263, 14323-14333.

Dowhan, W., Bibus, C. R. \& Schatz, G. (1985). The cytoplasmicallymade subunit-IV is necessary for assembly of cytochrome $c$ oxidase in yeast. $E M B O J 4,179-184$.

Dykens, J. A. \& Will, Y. (2007). The significance of mitochondrial toxicity testing in drug development. Drug Discov Today 12, 777-785.

Fendt, S. M. \& Sauer, U. (2010). Transcriptional regulation of respiration in yeast metabolizing differently repressive carbon substrates. BMC Syst Biol 4, 12.

Fosbøl, E. L., Gislason, G. H., Jacobsen, S., Folke, F., Hansen, M. L., Schramm, T. K., Sorensen, R., Rasmussen, J. N., Andersen, S. S. \& other authors (2009). Risk of myocardial infarction and death associated with the use of nonsteroidal anti-inflammatory drugs (NSAIDs) among healthy individuals: a nationwide cohort study. Clin Pharmacol Ther 85, 190-197.

Gietz, R. D. \& Sugino, A. (1988). New yeast-Escherichia-coli shuttle vectors constructed with in vitro mutagenized yeast genes lacking 6base pair restriction sites. Gene 74, 527-534.

Goldring, E. S., Grossman, L. I., Krupnick, D., Cryer, D. R. \& Marmur, J. (1970). The petite mutation in yeast. Loss of mitochondrial deoxyribonucleic acid during induction of petites with ethidium bromide. J Mol Biol 52, 323-335.

Gómez-Lechón, M. J., Ponsoda, X., O’Connor, E., Donato, T., Castell, J. V. \& Jover, R. (2003). Diclofenac induces apoptosis in hepatocytes by alteration of mitochondrial function and generation of ROS. Biochem Pharmacol 66, 2155-2167.

Guzy, R. D., Hoyos, B., Robin, E., Chen, H., Liu, L. P., Mansfield, K. D., Simon, M. C., Hammerling, U. \& Schumacker, P. T. (2005). Mitochondrial complex III is required for hypoxia-induced ROS production and cellular oxygen sensing. Cell Metab 1, 401-408.

Guzy, R. D., Mack, M. M. \& Schumacker, P. T. (2007). Mitochondrial complex III is required for hypoxia-induced ROS production and gene transcription in yeast. Antioxid Redox Signal 9, 1317-1328.

Hallstrom, T. C. \& Moye-Rowley, W. S. (2000). Multiple signals from dysfunctional mitochondria activate the pleiotropic drug resistance pathway in Saccharomyces cerevisiae. J Biol Chem 275, 37347-37356.

Inoue, A., Muranaka, S., Fujita, H., Kanno, T., Tamai, H. \& Utsumi, K. (2004). Molecular mechanism of diclofenac-induced apoptosis of promyelocytic leukemia: dependency on reactive oxygen species, Akt, Bid, cytochrome and caspase pathway. Free Radic Biol Med 37, 12901299.

Katzmann, D. J., Burnett, P. E., Golin, J., Mahe, Y. \& Moye-Rowley, W. S. (1994). Transcriptional control of the yeast PDR5 gene by the PDR3 gene product. Mol Cell Biol 14, 4653-4661.

Klebe, R. J., Harriss, J. V., Sharp, Z. D. \& Douglas, M. G. (1983). A general method for polyethylene-glycol-induced genetic-transformation of bacteria and yeast. Gene 25, 333-341.

Kowaltowski, A. J., de Souza-Pinto, N. C., Castilho, R. F. \& Vercesi, A. E. (2009). Mitochondria and reactive oxygen species. Free Radic Biol Med 47, 333-343.

Krause, M. M., Brand, M. D., Krauss, S., Meisel, C., Vergin, H., Burmester, G. R. \& Buttgereit, F. (2003). Nonsteroidal antiinflammatory drugs and a selective cyclooxygenase 2 inhibitor uncouple mitochondria in intact cells. Arthritis Rheum 48, 1438-1444.

Labbe, G., Pessayre, D. \& Fromenty, B. (2008). Drug-induced liver injury through mitochondrial dysfunction: mechanisms and detection during preclinical safety studies. Fundam Clin Pharmacol 22, 335-353.

Laine, L., Goldkind, L., Curtis, S. P., Connors, L. G., Yanqiong, Z. \& Cannon, C. P. (2009). How common is diclofenac-associated liver injury? Analysis of 17,289 arthritis patients in a long-term prospective clinical trial. Am J Gastroenterol 104, 356-362.

Lee, J. Y., Hwang, G. W. \& Naganuma, A. (2009). Rip1 enhances methylmercury toxicity through production of reactive oxygen species (ROS) in budding yeast. J Toxicol Sci 34, 715-717.

Lemire, B. D. \& Oyedotun, K. S. (2002). The Saccharomyces cerevisiae mitochondrial succinate: ubiquinone oxidoreductase. Biochim Biophys Acta 1553, 102-116.

Lenaz, G. \& Genova, M. L. (2010). Structure and organization of mitochondrial respiratory complexes: a new understanding of an old subject. Antioxid Redox Signal 12, 961-1008.

Lim, M. S., Lim, P. L., Gupta, R. \& Boelsterli, U. A. (2006). Critical role of free cytosolic calcium, but not uncoupling, in mitochondrial permeability transition and cell death induced by diclofenac oxidative 
metabolites in immortalized human hepatocytes. Toxicol Appl Pharmacol 217, 322-331.

Masubuchi, Y., Yamada, S. \& Horie, T. (2000). Possible mechanism of hepatocyte injury induced by diphenylamine and its structurally related nonsteroidal anti-inflammatory drugs. J Pharmacol Exp Ther 292, 982-987.

Masubuchi, Y., Nakayama, S. \& Horie, T. (2002). Role of mitochondrial permeability transition in diclofenac-induced hepatocyte injury in rats. Hepatology 35, 544-551.

McEwen, J. E., Ko, C., Kloeckner-Gruissem, B. \& Poyton, R. O. (1986). Nuclear functions required for cytochrome $c$ oxidase biogenesis in Saccharomyces cerevisiae. Characterization of mutants in 34 complementation groups. J Biol Chem 261, 11872-11879.

Mima, S., Ushijima, H., Hwang, H. J., Tsutsumi, S., Makise, M., Yamaguchi, Y., Tomofusa, T., Mizushima, H. \& Mizushima, T. (2007). Identification of the TPO1 gene in yeast, and its human orthologue TETRAN, which cause resistance to NSAIDs. FEBS Lett 581, 14571463.

Muller, F. L., Roberts, A. G., Bowman, M. K. \& Kramer, D. M. (2003). Architecture of the Qo site of the cytochrome $b c_{1}$ complex probed by superoxide production. Biochemistry 42, 6493-6499.

Nieminen, A. L., Byrne, A. M., Herman, B. \& Lemasters, J. J. (1997). Mitochondrial permeability transition in hepatocytes induced by $\mathrm{t}$ $\mathrm{BuOOH}$ : $\mathrm{NAD}(\mathrm{P}) \mathrm{H}$ and reactive oxygen species. Am J Physiol 272, C1286-C1294.

Niklas, J., Noor, F. \& Heinzle, E. (2009). Effects of drugs in subtoxic concentrations on the metabolic fluxes in human hepatoma cell line Hep G2. Toxicol Appl Pharmacol 240, 327-336.

Noverr, M. C., Phare, S. M., Toews, G. B., Coffey, M. J. \& Huffnagle, G. B. (2001). Pathogenic yeasts Cryptococcus neoformans and Candida albicans produce immunomodulatory prostaglandins. Infect Immun 69, 2957-2963.

Orij, R., Postmus, J., Ter Beek, A., Brul, S. \& Smits, G. J. (2009). In vivo measurement of cytosolic and mitochondrial $\mathrm{pH}$ using a $\mathrm{pH}$ sensitive GFP derivative in Saccharomyces cerevisiae reveals a relation between intracellular pH and growth. Microbiology 155, 268-278.

Poyton, R. O., Ball, K. A. \& Castello, P. R. (2009). Mitochondrial generation of free radicals and hypoxic signaling. Trends Endocrinol Metab 20, 332-340.
Rosenfeld, E. \& Beauvoit, B. (2003). Role of the non-respiratory pathways in the utilization of molecular oxygen by Saccharomyces cerevisiae. Yeast 20, 1115-1144.

Sapienza, K., Bannister, W. \& Balzan, R. (2008). Mitochondrial involvement in aspirin-induced apoptosis in yeast. Microbiology 154, 2740-2747.

Seo, B. B., Kitajima-Ihara, T., Chan, E. K., Scheffler, I. E., Matsuno-Yagi, A. \& Yagi, T. (1998). Molecular remedy of complex I defects: rotenone-insensitive internal NADH-quinone oxidoreductase of Saccharomyces cerevisiae mitochondria restores the NADH oxidase activity of complex I-deficient mammalian cells. Proc Natl Acad Sci U S A 95, 9167-9171.

Srikanth, C. V., Chakraborti, A. K. \& Bachhawat, A. K. (2005). Acetaminophen toxicity and resistance in the yeast Saccharomyces cerevisiae. Microbiology 151, 99-111.

Taanman, J. W. \& Capaldi, R. A. (1992). Purification of yeast cytochrome $c$ oxidase with a subunit composition resembling the mammalian enzyme. J Biol Chem 267, 22481-22485.

Turrens, J. F. (2003). Mitochondrial formation of reactive oxygen species. J Physiol 552, 335-344.

Wohnsland, F. \& Faller, B. (2001). High-throughput permeability $\mathrm{pH}$ profile and high-throughput alkane/water $\log P$ with artificial membranes. J Med Chem 44, 923-930.

Wright, R. M., Dircks, L. K. \& Poyton, R. O. (1986). Characterization of COX9, the nuclear gene encoding the yeast mitochondrial protein cytochrome $c$ oxidase subunit VIIa. Subunit VIIa lacks a leader peptide and is an essential component of the holoenzyme. J Biol Chem 261, 17183-17191.

Yang, S. Q., Ma, H. W., Yu, L. \& Yu, C. A. (2008). On the mechanism of quinol oxidation at the $\mathrm{Q}_{\mathrm{P}}$ site in the cytochrome $b c_{1}$ complex. Studied using mutants lacking cytochrome $b_{\mathrm{L}}$ or $b_{\mathrm{H}}$.J Biol Chem 283, 28767-28776.

Zara, V., Conte, L. \& Trumpower, B. L. (2009). Biogenesis of the yeast cytochrome bcl complex. Biochim Biophys Acta 1793, 89-96.

Zhang, X. \& Moye-Rowley, W. S. (2001). Saccharomyces cerevisiae multidrug resistance gene expression inversely correlates with the status of the $\mathrm{F}_{0}$ component of the mitochondrial ATPase. J Biol Chem 276, 47844-47852.

Edited by: M. Tien 